\title{
A Modular Cascaded Multilevel Inverter Based Shunt Hybrid Active Power Filter for Selective Harmonic and Reactive Power Compensation Under Distorted/Unbalanced Grid Voltage Conditions
}

\author{
T. Demirdelen \\ Cukurova University, Department of \\ Electrical and Electronics \\ Engineering, Balcali, Adana, Turkey \\ tdemirdelen@cu.edu.tr
}

\author{
R. I. Kayaalp \\ Cukurova University, Department of \\ Electrical and Electronics \\ Engineering, Balcali, Adana, Turkey \\ ikayaalp@cu.edu.tr
}

\author{
M. Tumay \\ Cukurova University, Department of \\ Electrical and Electronics \\ Engineering, Balcali, Adana, Turkey \\ mtumay@cu.edu.tr
}

\begin{abstract}
In recent years, shunt hybrid active power filters are being increasingly considered as a viable alternative to both passive filters and active power filters for compensating harmonics. In literature, their applications are restricted to balanced systems and low voltage applications and therefore not for industrial applications. This paper investigates the performance of a modular cascaded multilevel inverter based Shunt Hybrid Active Power Filter (SHAPF) for reactive power compensation and selective harmonics elimination under distorted/unbalanced grid voltage conditions in medium voltage levels. In the proposed control method, reactive power compensation is achieved successfully with a perceptible amount and the performance results of harmonic compensation are satisfactory. Theoretical analysis and simulation results are obtained from an actual industrial network model in PSCAD. The simulation results are presented for a proposed system in order to demonstrate that the harmonic compensation performance meets the IEEE-519 standard.
\end{abstract}

Keywords-harmonic compensation; medium voltage applications; modular cascaded multilevel inverter; reactive power compensation; shunt hybrid active power filter

\section{INTRODUCTION}

In recent years, high power equipment has been employed in industrial applications due to the megawatt power level for many medium voltage applications. Due to this condition, multilevel power converters are to be used as an alternative solution in medium and high voltage applications. Multilevel converters have the ability to increase the output voltage without raising the voltage rating of switching components. Thus, they are preferred to connect to medium voltage grids without using transformers. Among the various multilevel converters topologies, cascaded inverters consist of several converters connected in series. Thus, the high power and/or high voltage from the combination of the multiple modules would favor this topology in medium and high voltage applications. The modular multilevel inverter has been used as an alternative choice to conventional multilevel inverters. It has been designed to mitigate the drawbacks of conventional multilevel inverters such as the difficulty of balancing the capacitor voltage on higher order levels, the need for an output filter and interfacing transformer. Also conventional multilevel inverters are not capable of fault management and fault ride through.

The modular cascaded H-bridge multilevel inverter is one of the cascaded inverter topologies. The output multilevel voltage waveforms enable the reduction of harmonics in the synthesized current, reducing the size of the needed output filters. The cascaded multilevel inverter also has other advantages such as reduced voltage stresses on the semiconductor switches, as well as having higher efficiency when compared to other converter topologies [1]. Using identical power cells leads to a modular structure, which is an effective means for cost reduction. The aforementioned reasons caused to compose the modular cascaded multilevel inverter based SHAPF investigated in this paper.

The increase of nonlinear loads causes several power quality problems in power systems. The grid voltage and currents become non sinusoidal due to these types of loads. The traditional yet ineffective solution to reduce current harmonic distortion is passive filters. Active power filters have become a new research emphasis on power electronics technology as a new and improved solution to the problem. Hybrid active power filters effectively smooth the problems of passive filters and an active power filter solution may ensure a cost effective harmonic compensation.

Several hybrid APF (HAPF) topologies are introduced in $[2-10,13]$ for reactive power and harmonic current filtering. The most common topologies are shunt HAPF (SHAPF) [4-12] consisting of an APF and a passive filter connected in series with each other and series HAPF [3] which is a combined system of the shunt passive filter and a series APF. An extensive overview of the topological structures is given in [2, 
13]. Most articles describe research focused on low voltage levels. On the contrary, Multilevel SHAPF (M-SHAPF) [6-7, 11-12] is the most often used in medium voltage levels in industrial applications.

The controller design is the most important part due to its impact on the performance and stability of the overall system. For this reason, numerous control methods such as pq theory [4], dq theory [5-7, 12], fuzzy controller [8] etc... have been applied for the harmonic compensation in the literature. In literature, shunt hybrid active power filters [2-5, 8-10] are restricted to balanced systems and low voltage applications and thus cannot be employed for industrial applications. On account of the limitations between existing literatures, the purpose of this paper is the following:

1. To investigate the performance of the modular cascaded multilevel inverter based shunt hybrid active power filter for reactive power compensation and selective harmonics elimination under distorted/unbalanced grid voltage conditions.

2. To investigate the application of this control method in medium voltage levels.

3. To perform theoretical analysis and simulation results for an actual industrial network model in PSCAD.

4. To check the compliance of the results with the IEEE519 standard.

5. To apply dynamic load changes and observe the system response.

\section{PROPOSED SYSTEM AND CONTROLLER}

Figure 1 shows the detailed circuit configuration of the proposed system. As shown, a modular cascaded multilevel inverter unit is connected to the grid through a LC filter tuned on the vicinity of the 5th harmonic. As shown in Figure 2, the controller of the proposed system consists of six main parts: phase lock loop, harmonic reference generation, reactive current reference generation, selective harmonic reference generation, dc link voltage controller and final reference compensation current- pwm control block.

\section{A. Differential Phase Lock Loop}

The phase angle $(\theta)$ of the supply voltage is required which affects the performance of the control method. Hence, an accurate phase tracking system is the key point of the control method to transform the measured current vectors into synchronously rotating d-q reference frame. Thus, Dif-PLL is selected for extracting the phase angle $(\theta)$ [14] shown in Figure 2 (a).

\section{B. Harmonic Reference Generation}

The first step of harmonic current control is to isolate the harmonic components from the fundamental component of the grid currents. This is achieved through the dq transformation (2), synchronized with the PCC voltage vector, and a first order low pass filter (LPF) with cut off frequency of $10 \mathrm{~Hz}$. Then the dq inverse transformation (4) produces the harmonic currents in the abc referential frame shown in Figure 2 (b).
The conversion matrix is:

$$
\begin{gathered}
T_{\mathrm{d} q}^{123}=\sqrt{\frac{2}{3}}\left[\begin{array}{ccc}
\cos \theta_{p} & \cos \left(\theta_{p}-2 \pi / 3\right) & \cos \left(\theta_{p}+2 \pi / 3\right) \\
-\sin \theta_{p} & -\sin \left(\theta_{p}-2 \pi / 3\right) & -\sin \left(\theta_{p}+2 \pi / 3\right) \\
\frac{\sqrt{2}}{2} & \frac{\sqrt{2}}{2} & \frac{\sqrt{2}}{2}
\end{array}\right] \\
{\left[\begin{array}{c}
i_{d} \\
i_{q} \\
i_{o}
\end{array}\right]=T_{d q}^{123}\left[\begin{array}{l}
i_{S a} \\
i_{S b} \\
i_{S c}
\end{array}\right]}
\end{gathered}
$$

and the inverse conversion matrix is:

$$
\begin{aligned}
& T_{123}^{d q}=\sqrt{\frac{2}{3}}\left[\begin{array}{ccc}
\cos \theta_{p} & -\sin \theta_{p} & \frac{\sqrt{2}}{2} \\
\cos \left(\theta_{p}-2 \pi / 3\right) & -\sin \left(\theta_{p}-2 \pi / 3\right) & \frac{\sqrt{2}}{2} \\
\cos \left(\theta_{p}+2 \pi / 3\right) & -\sin \left(\theta_{p}+2 \pi / 3\right) & \frac{\sqrt{2}}{2}
\end{array}\right] \\
& {\left[\begin{array}{l}
i_{a_{-} \text {harmonic_ref }} \\
i_{b_{-} \text {harmonic_ref }} \\
i_{c_{-} \text {harmonic_ref }}
\end{array}\right]=T_{123}^{d q}\left[\begin{array}{l}
i_{d_{-} l p f} \\
i_{q_{-} l p f} \\
i_{o_{-} l p f}
\end{array}\right]}
\end{aligned}
$$

\section{Reactive Current Reference Generation}

The reference current provided the essential reactive power is produced. In order to achieve the reactive power compensation of M-SHAPF, the reference current having $90^{\circ}$ phase difference among the PCC point should be produced. To produce this reference current, the output voltage of M-SHAPF inverter should be generated in the phase with PCC voltage vector. The block diagram of reactive power control is shown in Figure 2(c).

$$
\begin{gathered}
{\left[\begin{array}{c}
i_{d} \\
i_{q} \\
i_{o}
\end{array}\right]=T_{d q}^{123}\left[\begin{array}{c}
i_{s a} \\
i_{s b} \\
i_{s c}
\end{array}\right] \quad(5)} \\
{\left[\begin{array}{c}
i_{a_{\text {_reactive_ref }}} \\
i_{b_{b} \text { reactive_ref }} \\
i_{c_{\text {_rreactive_ref }}}
\end{array}\right]=T_{123}^{\mathrm{dq}}\left[\begin{array}{c}
i_{q_{-} \text {fund }} \\
0 \\
0
\end{array}\right](6)}
\end{gathered}
$$

For the realization of the reactive power compensation, the reference currents should be calculated. The reference currents are generated by the dq method. The first step is to isolate the fundamental components from the harmonic components of the grid currents. This is achieved through the dq transformation (5). The quadrature component of the source current which is taken from dq transformation is directly passed through the LPF. Thus, the $50 \mathrm{~Hz}$ component of the source current is generated. Then this signal is applied to reproduce the reactive power compensation current by inversing the dq transformation (6). However, this reference current is in a quadrature axis. To achieve the reactive power compensation by the voltage controlled voltage source M-SHAPF, the reference current must be in the phase with the source voltage. Thus, the reference current is transformed by using only the 'd' component of the inverse dq transformation. 


\section{Selective Harmonic Reference Current Generation}

Selective harmonic elimination technique is generally based on the ideas of opposite harmonic injection (3rd, 5th, 7th, 9th,11th and 13th order) and it's given to three phase voltage source inverter switches. In this paper, the passive filter part of the system is tuned on the 5th harmonic frequency. In addition, SHAPF compensates harmonics. However, 7th, 9th, 11th and 13th harmonics are still in the system with small amount. Thus, FFT methods is used for eliminating this harmonics. Figure 2(d) represents the FFT based selective harmonic elimination. Firstly, 7th, 9th, 11th and 13th order harmonics are extracted by FFT. Then, three phase selective harmonic reference current is generated by using "sine" operator.

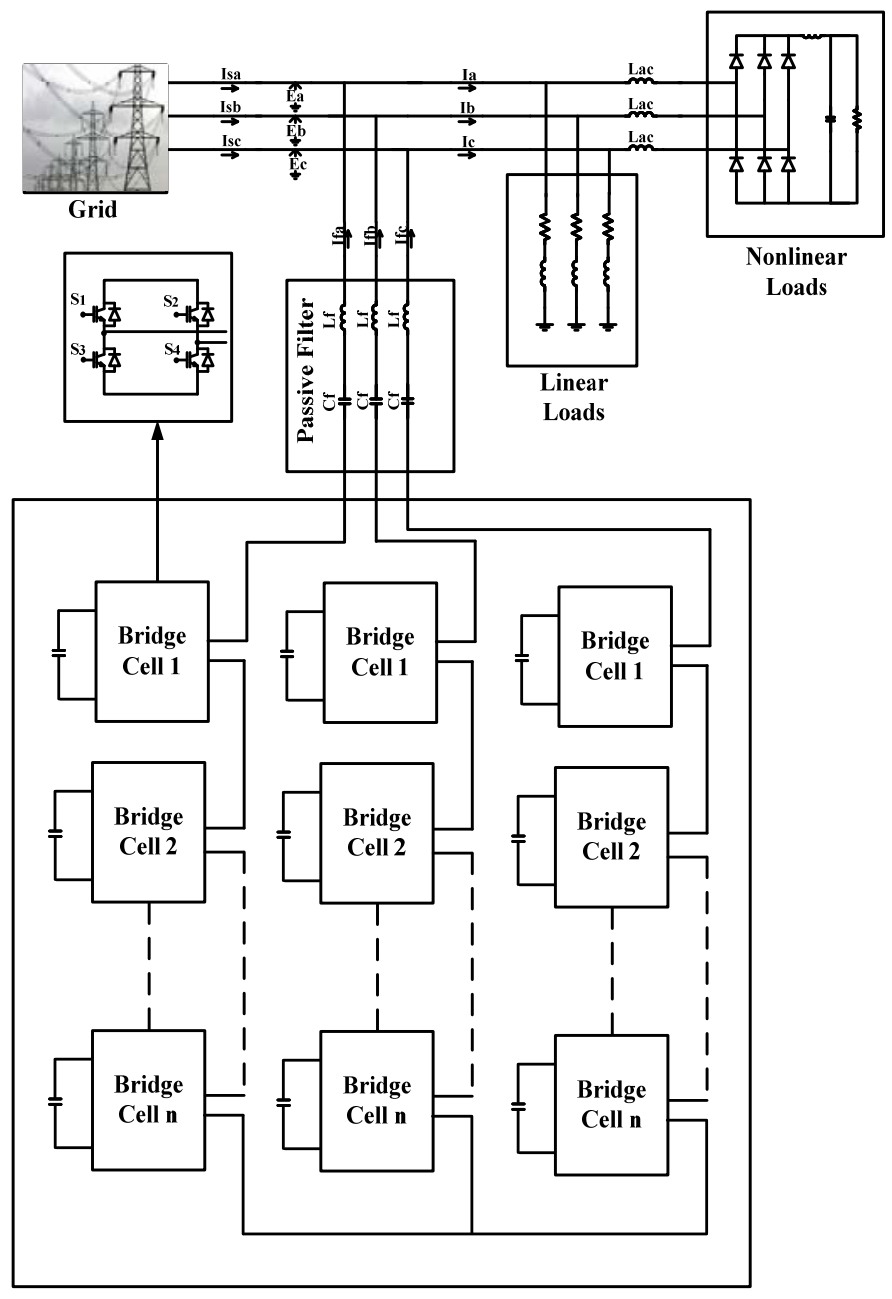

Fig. 1. Proposed System

\section{E. DC Link Voltage Controller}

$V_{D C}^{*}$ is the dc link reference value for both harmonic and reactive power compensation selected $1.5 \mathrm{kV}$. By using the error signal generated by the conventional PI controller, the dq inverse transformation (7) produces the reference DC link control signals in the abc referential frame shown in Figure 2 (e). A limiter is also applied to avoid the overflow problem of the controller. DC link is controlled by the reactive component of the error signal. Thus, only the q component is used for $\mathrm{dq}$ inverse transformation.

$$
\left[\begin{array}{c}
V_{\text {cappi_a }} \\
V_{\text {cappi_b }} \\
V_{\text {cappi_c }}
\end{array}\right]=T_{123}^{d q}\left[\begin{array}{c}
0 \\
V_{\text {errror }} \\
0
\end{array}\right]
$$

\section{F. Multilevel Inverter Control, Final Reference Compensation Current and PWM Control Block}

In this proposed system a seven level modular cascaded multilevel inverter is used. Cascaded multilevel inverters include series $\mathrm{H}$ bridge inverters. Cascaded inverters have structurally no problem of dc-link voltage unbalancing. Thus, the cascaded inverter has been widely studied and used in fields of static VAR compensators (SVCs), power line conditioners, voltage stabilizers and hybrid active power filters. To compare with the diode clamped or capacitor clamped inverter, the cascaded inverter does not need any voltage clamping diodes or voltage balancing capacitors. Table I shows the switch combination of seven level cascaded multilevel inverter.

TABLE I. SWITCH COMBINATION OF SEVEN LEVEL CASCADED MULTILEVEL INVERTER FOR EACH PHASE

\begin{tabular}{|c|c|c|c|c|c|c|c|c|c|c|c|c|}
\hline $\begin{array}{c}\text { Voltage } \\
\text { Vao }\end{array}$ & \multicolumn{10}{|c|}{ Switch State } \\
\cline { 2 - 15 } & $\mathbf{S}_{\mathbf{1}}$ & $\mathbf{S}_{\mathbf{2}}$ & $\mathbf{S}_{\mathbf{3}}$ & $\mathbf{S}_{\mathbf{4}}$ & $\mathbf{S}_{\mathbf{5}}$ & $\mathbf{S}_{\mathbf{6}}$ & $\mathbf{S}_{\mathbf{7}}$ & $\mathbf{S}_{\mathbf{8}}$ & $\mathbf{S}_{\mathbf{9}}$ & $\mathbf{S}_{\mathbf{1 0}}$ & $\mathbf{S}_{\mathbf{1 1}}$ & $\mathbf{S}_{\mathbf{1 2}}$ \\
\hline $3 \mathrm{~V}_{\mathrm{dc}}$ & 1 & 0 & 0 & 1 & 1 & 0 & 0 & 1 & 1 & 0 & 0 & 1 \\
\hline $2 \mathrm{~V}_{\mathrm{dc}}$ & 1 & 0 & 0 & 1 & 1 & 0 & 0 & 1 & 0 & 0 & 1 & 1 \\
\hline $\mathrm{V}_{\mathrm{dc}}$ & 1 & 0 & 0 & 1 & 0 & 0 & 1 & 1 & 0 & 0 & 1 & 1 \\
\hline 0 & 0 & 0 & 1 & 1 & 0 & 0 & 1 & 1 & 0 & 0 & 1 & 1 \\
\hline$-\mathrm{V}_{\mathrm{dc}}$ & 0 & 0 & 1 & 1 & 0 & 0 & 1 & 1 & 0 & 1 & 1 & 0 \\
\hline$-2 \mathrm{~V}_{\mathrm{dc}}$ & 0 & 0 & 1 & 1 & 0 & 1 & 1 & 0 & 0 & 1 & 1 & 0 \\
\hline$-3 \mathrm{~V}_{\mathrm{dc}}$ & 0 & 1 & 1 & 0 & 0 & 1 & 1 & 0 & 0 & 1 & 1 & 0 \\
\hline
\end{tabular}

The final reference current consists of three phase harmonic reference current signals, three phase selective harmonic reference current signals, three phase reactive reference current signals and dc link control signals. The reference signal (In_harmonic_ref + In_fft_k_ref + In_reactive_ref + Vcappi_n) is generated using these signals together. Then, the reference signals are compared with carrier signals to generate switching signals shown in in Figure 2(f).

\section{Simulation Results}

The simulation studies are carried out using PSCAD/EMTDC (three runs), aiming to evaluate the effectiveness and correctness of the control strategy used in the SHAPF under unbalanced/distorted grid voltage. The simulation parameters are given in Table II. The passive filters are tuned at 5 th and the control signals of IGBTs are generated through the pulse width modulation generator whose amplitude and frequency of carrier wave are \pm 1 and $10 \mathrm{kHz}$, 
respectively.
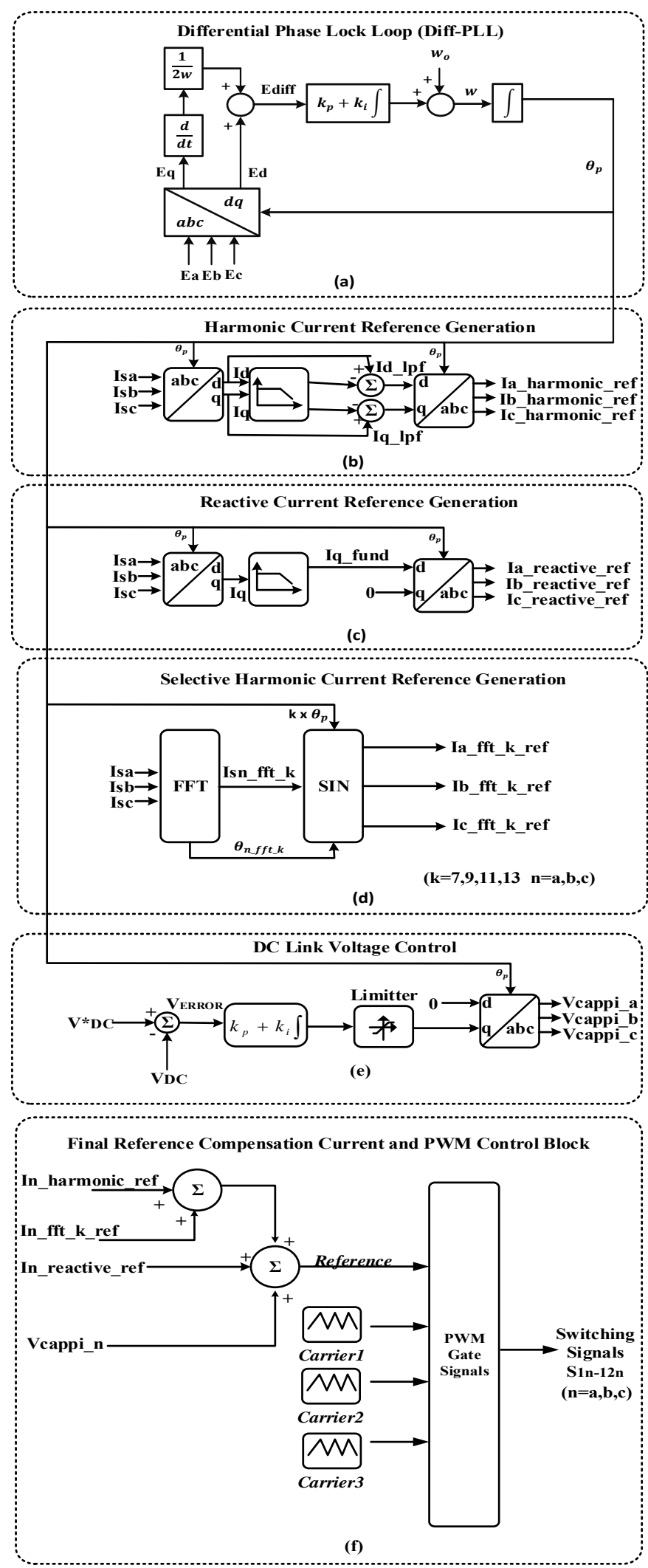

Fig. 2. Proposed Controller
TABLE II.

\begin{tabular}{|c|c|}
\hline Parameters & Value \\
\hline Line Voltage & $6.3 \mathrm{kV}$ \\
\hline Line frequency & $50 \mathrm{~Hz}$ \\
\hline Supply inductance (Ls) & $1 \mathrm{mH}$ \\
\hline Rectifier inductance (Ll) & $0.6 \mathrm{mH}$ \\
\hline Filter (CF,LF) & $16 \mu \mathrm{F}, 25 \mathrm{mH}$ \\
\hline Load Resistances(Rload1) & $100 \Omega$ \\
\hline Load Inductances(Lload1) & $600 \mathrm{mH}$ \\
\hline Load Inductances(Lac1) & $13 \mathrm{mH}$ \\
\hline Switching frequency (fswitching) & $10 \mathrm{kHz}$ \\
\hline Simulation Step Time & $20 \mu \mathrm{s}$ \\
\hline Inductive Loads 1st Load (Rload1 Lload1) & $360 \mathrm{kVAR}$ \\
\hline Nonlinear Load & $60 \mathrm{kVAR}$ \\
\hline Tuned freq. of series filter (ftuned) & $250 \mathrm{~Hz}$ \\
\hline
\end{tabular}

First case is that three phase grid voltages are balanced. It is ideal condition and in literature most articles consider this condition. As shown in Figure 3, the harmonic elements of the grid currents are almost eliminated. In the second case, one phase of grid voltages is distorted. $10 \%$ and $11^{\text {th }}$ order harmonics is added to Phase A voltage. As shown in Figure 4, the reduced THD of the source current, while compensating harmonics, working distorted supply means, sinusoidal current is drawn from the source. Last case is that the grid voltages are unbalanced as the case in industrial applications. Phase $\mathrm{C}$ voltage has a lower value compared to other phase voltages. As shown in Figure 5, the harmonic elements of the grid currents are almost eliminated.

Figure 6 represents that the source reactive power is nearly equal to zero for all cases. The passive filter supports a fixed reactive power which is equal to $220 \mathrm{kVAR}$. The load reactive power capacity is nearly $320 \mathrm{kVAR}$. Thus, the inverter part of SHAPF supplies the remaining reactive power compensation which is nearly equal to $100 \mathrm{kVAR}$. The SHAPF DC link voltage is stable for all cases shown as shown in Figure 6.

Considering the simulation results, the proposed method can:

- Provide reactive power and harmonic compensation

- $\quad$ Reduce the THD of the source side current

- Apply for medium voltage applications

- work not only with distorted but also with unbalance grid voltages.

\section{CONCLUSION}

A new control approach is investigated in order to ensure the ac current shaping, compensate the reactive power and regulate the dc voltage for a three phase modular cascaded multilevel inverter based shunt hybrid active power filter. The harmonic compensation is obtained by regulating the currents of the power systems. The reference reactive power compensation currents of the M-SHAPF are generated indirectly of the power systems. The dc link voltage control signals are based on the reactive power balance of system. The reactive power compensation is achieved successfully with a perceptible amount. The selective harmonic compensation 
performance is satisfactory. The simulation results of the three phase three wire SHAPF are illustrated to verify all discussion and analysis and also show the effectiveness of the proposed controller. Hence, the proposed M-SHAPF system can be considered an effective and economic solution for both harmonic and reactive power problems caused by the large capacity of linear and nonlinear loads under balanced, unbalanced and distorted grid voltages.

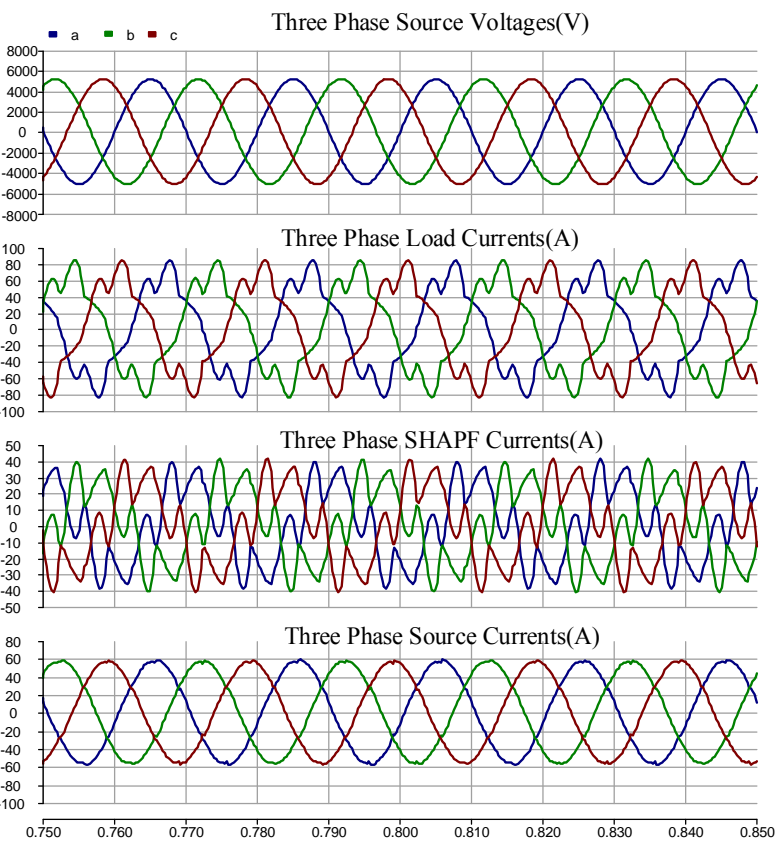

Fig. 3. Three Phase Source Voltages, Load Currents, SHAPF Current and Source Currents under balanced grid voltage

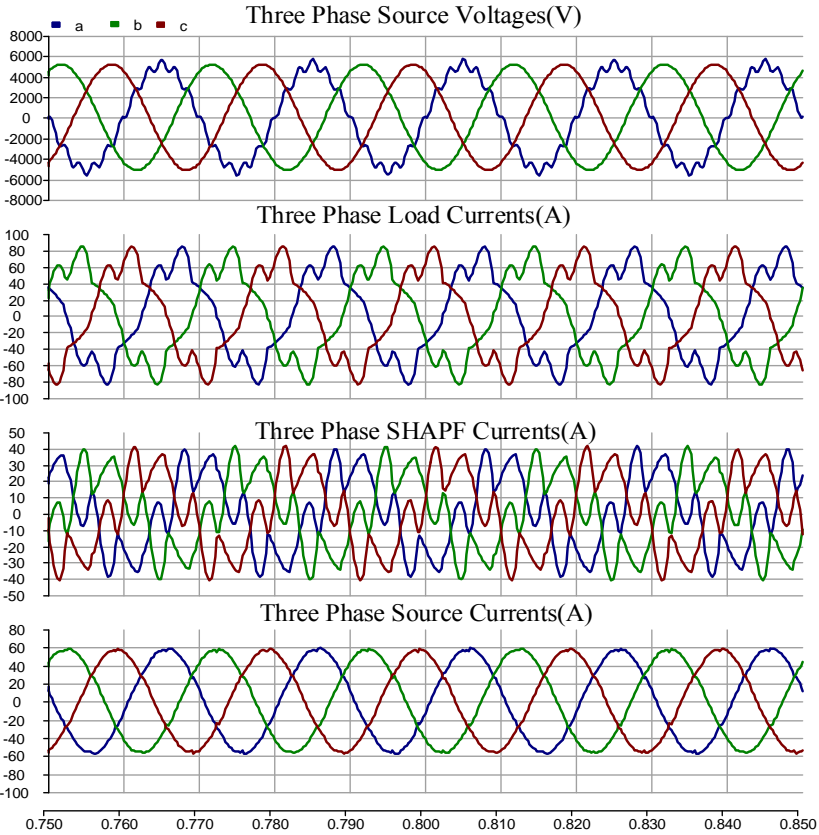

Fig. 4. Three Phase Source Voltages, Load Currents, SHAPF Current and Source Currents distorted grid voltage

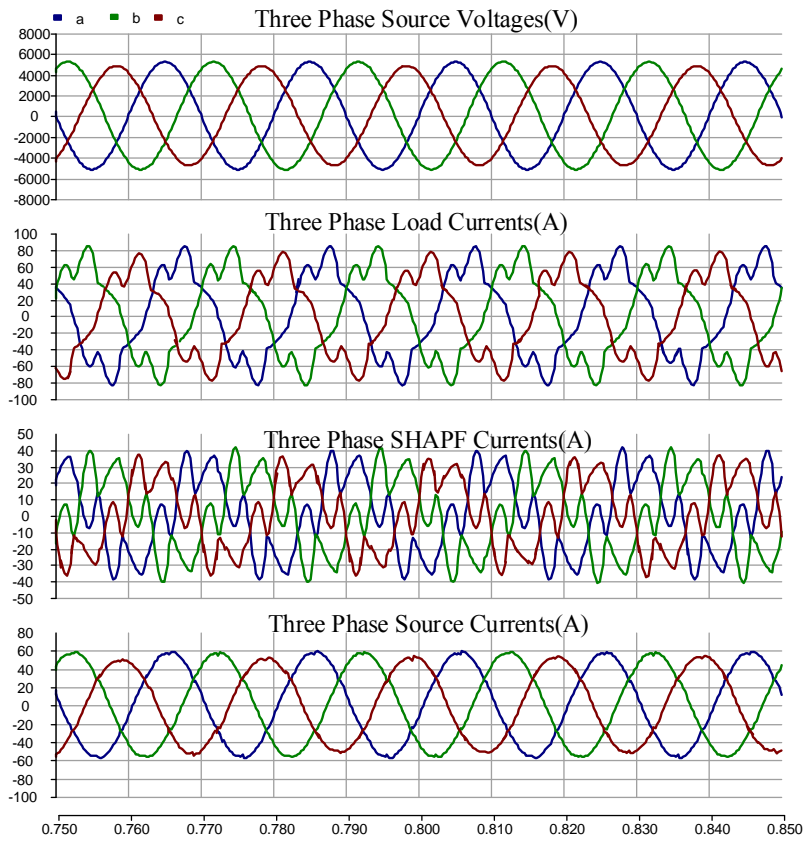

Fig. 5. Three Phase Source Voltages, Load Currents, SHAPF Current and Source Currents under unbalanced grid voltage

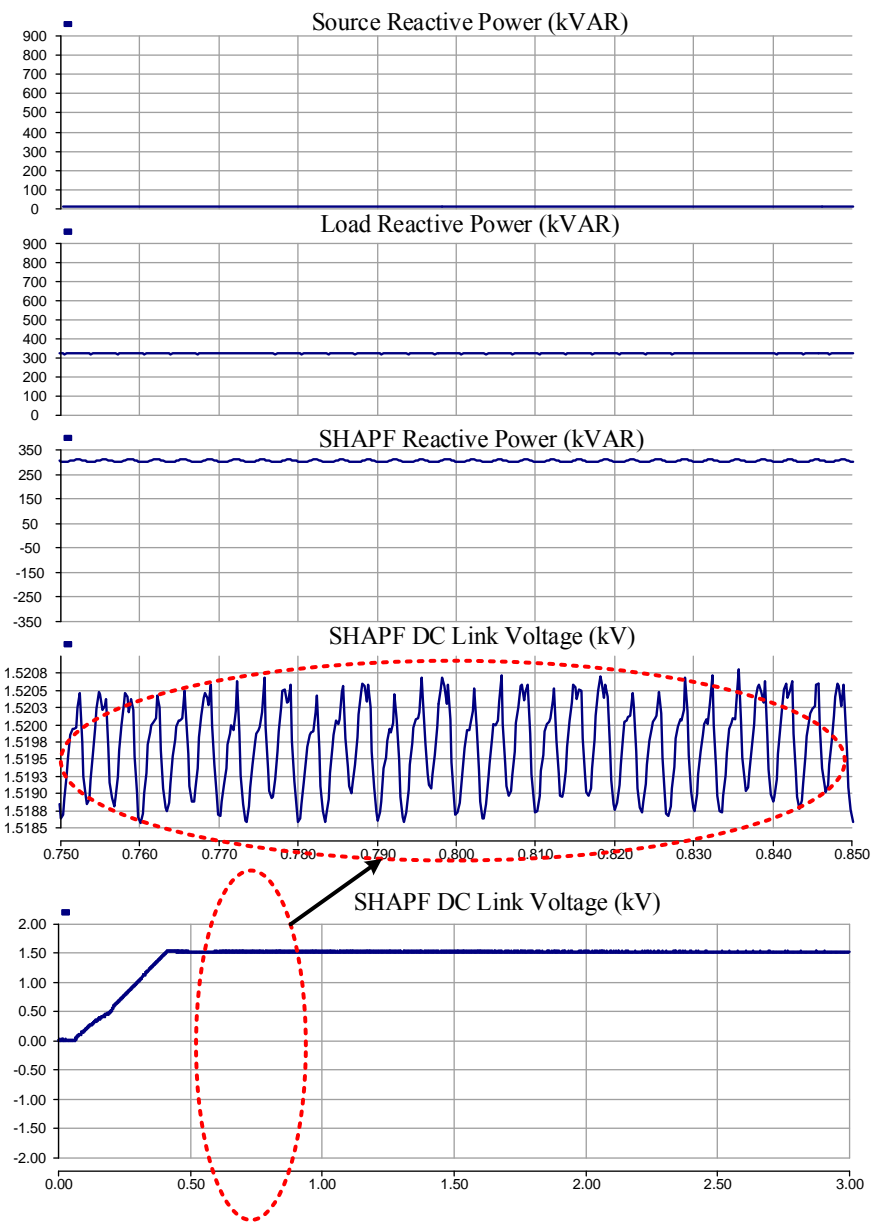

Fig. 6. Source, Load, SHAPF reactive power and SHAPF DC link Voltage 


\section{ACKNOWLEDGMENT}

The authors would like to acknowledge the Scientific and Technological Research Council of Turkey (TÜBİTAK Project Number: 115R327) and the Scientific Project Unit of Cukurova University (FDK-2016-5828) for full financial support.

\section{REFERENCES}

[1] X. Bails, L.M. Tolbert,"Efficiency improved and current balanced threephase modular cascaded $\mathrm{H}$ bridge multilevel PV inverter for grid connected applications", IEEE Energy Conversion Congress and Exposition (ECCE), pp. 4661-4669, 2014

[2] J. Turunen, M. Salo, H. Tuusa, "Comparison of three series hybrid active power filter topologies", 11th International Conference on. Harmonics and Quality of Power, pp. 324-329, Sept. 2004

[3] D. Shaojun, L. Jianben, T. Kun, C. Qiaofu, "Modelling and industrial application of series hybrid active power filter", IET Power Electronics, Vol. 6, No. 8, pp. 1707-1714, 2013

[4] C. S. Lam, W. H. Choi, M. C. Wong, Y. D. Han, "Adaptive DC-Link Voltage-Controlled Hybrid Active Power Filters for Reactive Power Compensation", IEEE Transactions on Power Electronics, Vol. 27, No. 4, pp.1758-1772, 2012

[5] S. Rahmani, A. Hamadi, K. Al-Haddad, L. A. Dessaint, "A Combination of Shunt Hybrid Power Filter and Thyristor-Controlled Reactor for Power Quality", IEEE Transactions on Industrial Electronics, Vol. 61, No. 5, pp. 2152-2164, 2014

[6] S. Srianthumrong, H. Akagi, "A Medium Voltage Transformerless AC/DC Power Conversion System Consisting of a Diode Rectifier and a Shunt Hybrid Filter", IEEE Transactions on Industry Applications, Vol. 39, No. 3, pp. 874-882, 2003

[7] N. Hatti, K. Hasegawa, H. Akagi, "A 6.6-kV Transformerless Motor Drive Using a Five-Level Diode-Clamped PWM Inverter for Energy
Savings of Pumps and Blowers", IEEE Transactions on Power Electronics, Vol. 24, No. 3, pp. 796-803, 2009

[8] J. Wu, A. Luo, S. Peng, F. Ma, Z. Zeng, M. T. Chau, "System control of hybrid active power filter for reactive power compensation and harmonic suppression", 6th IEEE Conference on Industrial Electronics and Applications (ICIEA), pp. 862-866, Beijing, China, 2011

[9] L. Herman, I. Papic, B. Blazic, "A Proportional-Resonant Current Controller for Selective Harmonic Compensation in a Hybrid Active Power Filter", IEEE Transactions on Power Delivery, Vol. 29, No. 5, pp. 2055-2065, 2014

[10] M. Salehifar, A. Shoulaie, "Hybrid active filter for harmonic suppression and reactive power compensation", 2009 International Conference for Technical Postgraduates (TECHPOS), pp. 1-4, 2009

[11] A. M. Massoud, S. J. Finney, A. J. Cruden, B. W. Williams, “ThreePhase, Three-Wire, Five-Level Cascaded Shunt Active Filter for Power Conditioning, Using Two Different Space Vector Modulation Techniques," IEEE Transactions on Power Delivery, Vol. 22, No. 4, pp. 2349-2361, 2007

[12] T. Demirdelen, R. I. Kayaalp, M. Tumay, "Modeling and Analysis of a Multilevel Parallel Hybrid Active Power Filter", Engineering, Technology \& Applied Science Research, Vol. 6, No. 3, pp. 976-981, 2016

[13] T. Demirdelen, M. Inci, K. Cagatay Bayindir, M. Tumay, "Review of hybrid active power filter topologies and controllers", Fourth International Conference on Power Engineering, Energy and Electrical Drives (POWERENG), pp. 587-592, May 13-17, 2013

[14] M. E. Meral, "Improved phase-locked loop for robust and fast tracking of three phases under unbalanced electric grid conditions", IET Generation, Transmission \& Distribution, Vol. 6, No. 2, pp. 152-160, 2012 